\title{
EFEITOS DO PASTOREIO DE BOVINOS NA ESTRUTURA POPULACIONAL DE PLANTAS EM FRAGMENTOS DE FLORESTA OMBRÓFILA MISTA ${ }^{1}$
}

\author{
Maurício Bonesso Sampaio² e Ernestino de Souza Gomes Guarino ${ }^{3}$
}

\begin{abstract}
RESUMO - Fragmentos de Floresta Ombrófila Mista têm sido freqüentemente utilizados para o manejo de bovinos na região do médio rio Pelotas, Sul do Brasil. Para avaliar o efeito dos animais na estrutura populacional de Araucaria angustifolia, Clethra scabra, Dicksonia sellowiana e Maytenus ilicifolia, foram amostrados sítios, sujeitos à alta e baixa intensidade de pastoreio, em cinco fragmentos, utilizando-se parcelas de 20 x $20 \mathrm{~m}$. Apesar do pequeno tamanho dos fragmentos e da alta perturbação pelo manejo do gado e pela extração seletiva de madeira, as espécies ocorreram em abundância, e a densidade de plântulas e infantis foi maior do que de árvores. O efeito do gado na estrutura das populações de $A$. angustifolia variou em função das características ambientais de cada fragmento, não havendo, assim, um padrão na resposta das populações estudadas ao pastoreio. Com relação às demais espécies, os resultados não foram conclusivos, pois ocorreram em alta densidade apenas em um fragmento.
\end{abstract}

Palavras-chave: Espécies ameaçadas, heterogeneidade ambiental e conservação in situ.

\section{EFFECT OF CATTLE GRAZING ON PLANT POPULATION STRUCTURE IN ARAUCARIA FOREST FRAGMENTS}

\begin{abstract}
Araucaria Forest fragments have been used for cattle grazing in the Pelotas River basin. We sampled five fragments using $20 \times 20 \mathrm{~m}$ plots to evaluate the effects of cattle grazing on the population structure of Araucaria angustifolia, Clethra scabra, Dicksonia sellowiana and Maytenus ilicifolia. Despite the small size of the fragments and the high intensity of cattle grazing and selective logging, the species occurred in abundance and had higher seedling and sapling density than did the trees. The effects of cattle grazing on the population structure of A. angustifolia were influenced by the habitat heterogeneity of each fragment, thus a reliable pattern could not be found. Since the other species occurred abundantly in only one fragment, the results obtained were not conclusive.
\end{abstract}

Keywords: Endangered species, fragmentation and in situ conservation.

\section{INTRODUÇÃO}

Fragmentos de Floresta Ombrófila Mista, remanescentes em fazendas do sul do Brasil, são freqüientemente utilizados como áreas de pastoreio para bovinos criados extensivamente (MAUHS, 2002; LIEBSCHe ACRA, 2004; MACHADO, 2004), sobretudo no inverno, quando as pastagens possuem baixa biomassa verde. Além disso, os fragmentos também têm sido utilizados pelo gado como abrigo contra temperaturas extremas, tanto no inverno quanto no verão.

Uma vez dentro do fragmento, o gado alimentase de folhas, frutos e sementes palatáveis. Além disso, pisoteia as plântulas e compacta o solo, dificultando a germinação das sementes e o crescimento das plântulas (WILSON, 1994). Assim, as espécies suscetíveis a essa intervenção apresentam alta mortalidade de indivíduos

\footnotetext{
${ }^{1}$ Recebido em 19.03.2007 e aceito para publicação em 25.06.2007.

${ }^{2}$ Embrapa Recursos Genéticos e Biotecnologia, Parque Estação Biológica, Av. W5 Norte (final), 70770-900 Brasí́lia-DF. E-mail: <mauriciobonesso@gmail.com>.

${ }^{3}$ Programa de Pós-Graduação em Botânica da Universidade Federal do Rio Grande do Sul.. E-mail: <esguarino@ gmail.com>.
} 
e baixo estabelecimento de plântulas, o que causa a redução no tamanho de suas populações. Entretanto, existem espécies cujo estabelecimento e sobrevivência das plântulas não são influenciados pelo pastoreio. Por exemplo, plântulas de Araucaria cunninghamii Aiton ex D. Don em um sistema silvopastoril na Austrália, mesmo com apenas $15 \mathrm{~cm}$ de altura, dificilmente são pisoteadas ou predadas pelo gado, provavelmente por possuírem folhas de ápice pontiagudo, que dificulta a herbivoria e até mesmo seu pisoteio (SUN et al., 1997). Espécies como essa, resistentes ao pastoreio, tendem a ser beneficiadas pela redução na competição interespecífica, proporcionada pela eliminação de indivíduos das espécies suscetíveis (KLEIJN e STEINGER, 2002; MILLER e WELLS, 2003; EVANS et al., 2006), que, desse modo, apresentam menor proporção de exemplares nos estágios iniciais do ciclo de vida.

O efeito de fatores como a intensidade de pastoreio, na persistência em longo prazo de uma população vegetal, pode ser avaliado através da estrutura populacional, que é a distribuição de freqüência dos indivíduos em classes de tamanho ou em estágios de vida (GATSUK et al., 1980). A estrutura populacional reflete eventos de mortalidade de indivíduos que ocorrem atualmente ou ocorreram no passado (WATKINSON, 1997).

A maioria dos estudos realizados para testar o efeito do manejo do gado na estrutura populacional foi desenhada para comparar populações em diferentes fragmentos submetidos a um gradiente de intensidades de pastoreio (RELVA e VEBLEN, 1998; VARGAS et al., 2002; MILLER e WELLS, 2003). Entretanto, pode haver alta variação espacial na estrutura de populações vegetais, devido à heterogeneidade nas condições ambientais entre fragmentos, mesmo naqueles não sujeitos a intervenções antrópicas (HEGLAND et al., 2001). Assim, os resultados desses estudos seriam mais influenciados por diferenças ambientais do que pelo pastoreio. Para que as variações na estrutura de populações possam ser atribuídas com maior confiança ao manejo do gado, é imprescindível comparar conjuntos de indivíduos de uma mesma espécie (populações) em sítios de um mesmo fragmento, submetidos a diferentes intensidades de pastoreio por um longo período de tempo, para que os fatores ambientais que influenciam essas populações tenham a maior homogeneidade possível entre sítios.

Historicamente, a maioria dos fragmentos de Floresta Ombrófila Mista no médio rio Pelotas vem sendo utilizada para o manejo de bovinos, portanto é importante avaliar o efeito do pastoreio na estrutura de populações para subsidiar a indicação de áreas efetivas para conservação in situ de espécies vegetais.

Com base no exposto, o objetivo deste estudo foi avaliar o efeito do pastoreio de bovinos através da comparação da estrutura populacional de plantas entre sítios com diferentes intensidades de uso pelos animais em um mesmo fragmento. Além disso, buscouse avaliar a influência da heterogeneidade ambiental no efeito do manejo do gado nessas populações.

\section{MATERIAL E MÉTODOS}

\section{1. Área de estudo}

Porção média da bacia do rio Pelotas $\left(27^{\circ} 41^{\prime}\right.$ a $28^{\circ} 22^{\prime} \mathrm{S} ; 51^{\circ} 07^{\prime}$ a $50^{\circ} 47^{\prime} \mathrm{W}$ ), que é o maior dos tributários do rio Uruguai. Os cinco fragmentos estudados localizamse nos Municípios de Anita Garibaldi (Pinheiros Ralos) e Campo Belo do Sul (Gateados), em Santa Catarina, e Pinhal da Serra (Ipê e São Cristóvão) e Vacaria (Cachoeirinha), no Rio Grande do Sul. As altitudes da região variam entre $500 \mathrm{~m}$ nas margens do rio Pelotas a até mais de $1.000 \mathrm{~m}$ no Planalto Serrano catarinense (SC) e nos Campos de Cima da Serra (RS), porém nos fragmentos estudados a altitude média é em torno de $800 \mathrm{~m}$. O relevo varia de suave-ondulado na região do Planalto, onde predominam os Cambissolos e a Terra Bruna Estruturada, a acidentado nas margens do rio Pelotas, onde as principais classes de solo são os Litólicos, com encraves de Terra Bruna Estruturada (POTTER et al., 2004). O clima é mesotérmico, subtropical úmido (Cfb na classificação de Köppen), com precipitação anual de $1.412 \mathrm{~mm}$ e temperatura média anual de $15,2{ }^{\circ} \mathrm{C}$ (MALUF, 2000).

A bacia do rio Pelotas é umas das 147 áreas prioritárias para a conservação da flora da Mata Atlântica, sendo uma das 79 áreas de extrema importância biológica (BRASIL, 2000). Nesta região, encontram-se três fisionomias vegetais naturais, das quais, duas são florestais e uma campestre. A primeira e mais conhecida é a Floresta Ombrófila Mista ou simplesmente Floresta de Araucária (VELOSO et al., 1991). Na área de estudo, essa fisionomia florestal encontra-se principalmente no Planalto Serrano catarinense e na região dos Campos de Cima da Serra no Rio Grande do Sul, em ambas as 
regiões esta fisionomia é naturalmente fragmentada pela ocorrência de Campos Naturais (KLEIN, 1978). A última fisionomia encontrada na região é a Floresta Estacional Semidecidual (VELOSO et al., 1991), que se concentra em áreas de elevada inclinação do relevo, principalmente nas margens do rio Pelotas.

\subsection{Procedimentos metodológicos}

Nos cinco fragmentos de Floresta Ombrófila Mista amostrados, quatro (Cachoeirinha, Ipê, Pinheiros Ralos e São Cristóvão) possuíam sítios contíguos submetidos a diferentes intensidades de pastoreio (doravante denominada apenas por IP), separados através de cercas de arame ou taipa (muro de pedra), evitando a passagem do gado entre sítios, há pelo menos 40 anos (Quadro 1). Há sinais de pastoreio em ambos os sítios de um mesmo fragmento, entretanto, um sítio é sujeito à alta IP, enquanto o outro tem baixa IP. No fragmento Gateados, o gado não entrava há mais de 13 anos (Quadro 1).

Em cada um dos fragmentos submetidos ao pastoreio foram alocadas de 14 a 20 parcelas (dependendo do tamanho e forma do fragmento) de 20 x 20 m, para a amostragem da estrutura de populações das espécies, sendo metade das parcelas estabelecidas no sítio com baixa IP e as demais no sítio com alta IP (Figura 1). A localização das parcelas foi sorteada em transectos de 60 a $120 \mathrm{~m}$ de comprimento em cada sítio, de forma que ficassem pelo menos $20 \mathrm{~m}$ distantes uma da outra (Figura 1). No fragmento Gateados foram alocadas aleatoriamente 11 parcelas, em uma trilha de $500 \mathrm{~m}$ de comprimento.

Em cada parcela foram amostrados os indivíduos de quatro espécies: 1) Araucaria angustifolia (Bertol.) Kuntze (pinheiro-do-paraná) - espécie arbórea cuja madeira e sementes apresentam importância econômica, listada como ameaçada de extinção devido à perda de habitat (IBAMA, 1992; SEMA, 2002; IUCN, 2006); 2) Clethra scabra Pers. (carne-de-vaca) - espécie arbórea considerada endêmica (SEMA, 2002); 3) Dicksonia sellowiana Hook. (xaxim) - pteridófita arborescente com grande importância econômica e ameaçada de extinção (IBAMA, 1992; SEMA, 2002) e; 4) Maytenus ilicifolia (Schrad.) Planch. (espinheira-santa) - arbusto que, apesar de não ser ameaçado de extinção, tem uso medicinal (LEITE et al., 2001; CIPRIANI et al., 2006; VELLOSA et al., 2006), e suas folhas são muito coletadas na região.
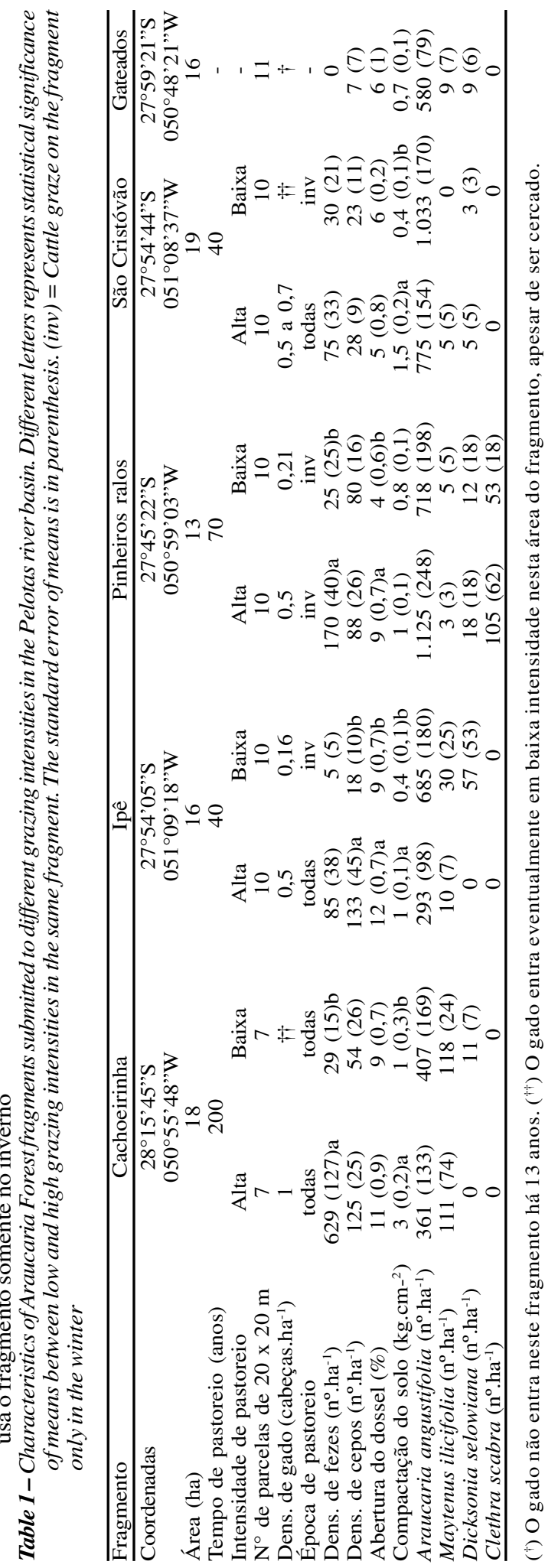

R. Árvore, Viçosa-MG, v.31, n.6, p.1035-1046, 2007 


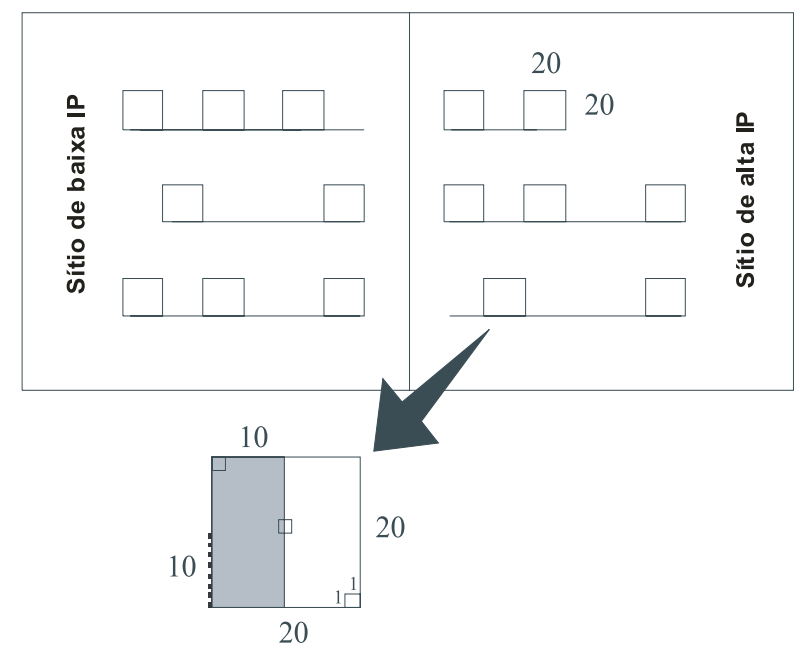

Figura 1 - Exemplo de distribuição das parcelas de 20 × 20 $\mathrm{m}$ em sítios de baixa e alta intensidade de pastoreio (IP) em um único fragmento. No desenho inferior são apresentadas, em detalhe, as subamostras em cada parcela. $\mathrm{Na}$ área em cinza $(10 \times 20 \mathrm{~m})$ foi contada a quantidade de fezes e nas três subparcelas de $1 \times 1 \mathrm{~m}$, medidas a compactação do solo e a abertura do dossel. A linha pontilhada, no canto inferior esquerdo da parcela, representa o transecto de $10 \mathrm{~m}$, onde foi estimada a porcentagem de cobertura do solo.

Figure 1 - Experimental design sampling population structure in fragments with low and high cattle grazing intensity. The sub-samples in each plot are showed in the lower drawing. The amount of cattle excrement was determined in the gray area $(10 \times 20 \mathrm{~m})$ and soil compaction and canopy density were measured in three $1 x 1 \mathrm{~m}$ sub-samples. Ground cover percentage was estimated in the $10 \mathrm{~m}$ transect in the dotted line.

Os indivíduos foram medidos quanto a altura e diâmetro ao nível do solo (DAS) e classificados em estágios de vida, para facilitar a comparação da estrutura populacional entre sítios de diferentes IP. Em cada espécie foram utilizados diferentes critérios de classificação, pois possuíam portes distintos. Os critérios utilizados para Araucaria angustifolia foram semelhantes aos adotados por Burns (1993) e Enright et al. (2003) para as coníferas Araucaria araucana (Molina) C. Koch e Agathis ovata (C. Moore ex Vieill.) Warb., respectivamente: plântula (altura $<30 \mathrm{~cm}$ ); infantil (30 a $100 \mathrm{~cm}$ de altura); jovem (altura $>100 \mathrm{~cm}$ e DAS < $5 \mathrm{~cm}$ ); arvoreta (5 a $30 \mathrm{~cm}$ de DAS); e árvore (DAS $>30 \mathrm{~cm}$ ). Os indivíduos de Maytenus ilicifolia foram classificados em: plântula (altura $<0,2 \mathrm{~m})$; infantil $(0,2$ a $0,5 \mathrm{~m}$ de altura); jovem (0,5 a $1 \mathrm{~m}$ de altura); arvoreta ( 1 a $2 \mathrm{~m}$ de altura); e arbusto ( $>2 \mathrm{~m}$ de altura). Os indivíduos de Clethra scabra foram classificados em: plântula (altura $<30 \mathrm{~cm}$ ); infantil (30 a $100 \mathrm{~cm}$ de altura); jovem (altura $>100 \mathrm{~cm}$ e DAS $<5 \mathrm{~cm}$ ); $\operatorname{arvoreta}(5 \mathrm{a}$ $10 \mathrm{~cm}$ de DAS); e árvore (DAS $>10 \mathrm{~cm}$ ). Como os indivíduos de Dicksonia sellowiana ocorreram em baixa densidade (ver resultados e discussão), não foram classificados em estágios de vida.

O histórico de perturbação e a densidade média de gado foram obtidos através de entrevistas com os proprietários das fazendas. Adicionalmente, foram estimadas variáveis ambientais relacionadas à IP em cada parcela. As fezes de gado foram contadas em uma subparcela de 10 x 20 m (Figura 1). A compactação do solo foi estimada utilizando-se um penetrômetro de bolso (Forestry Suppliers, Inc.), através de quatro leituras em três subparcelas de um metro quadrado. Nessas três subparcelas de $1 \times 1 \mathrm{~m}$ também foi estimada a abertura do dossel a $50 \mathrm{~cm}$ do solo, utilizando-se um densiômetro esférico (LEMMON, 1957). Foi estimada a porcentagem de cobertura do solo por diferentes formas de vida (gramíneas, plântulas de espécies lenhosas, herbáceas, pteridófitas etc.), através do método de interceptação de linha (BROWER et al., 1989), com o uso de uma trena de $10 \mathrm{~m}$ de comprimento esticada em um dos lados de cada parcela. Além disso, foi contado o número de cepos (pedaço do tronco que permanece no solo após o corte de uma árvore) na parcela inteira, variável indicadora da extração seletiva de madeira.

\section{RESULTADOS E DISCUSSÃO}

\subsection{Heterogeneidade ambiental}

Os cinco fragmentos estudados possuíam diferentes históricos de perturbação, principalmente devido à sua utilização para o manejo do gado e pela extração seletiva de madeira (Quadro 1). O fragmento Cachoeirinha foi submetido por mais tempo ao pastoreio (cerca de 200 anos). Além disso, teve maior densidade de gado e, conseqüentemente, apresentou maior densidade de fezes. Nesse fragmento, a compactação do solo diferiu significativamente entre sítios com diferentes IPs (Quadro 1).

O fragmento ipê teve extração seletiva de madeira em maior intensidade ou mais recentemente, o que é evidenciado pela alta densidade de cepos encontrada. 
Nesse fragmento, a densidade de cepos foi maior no sítio com alta IP do que baixa IP. Nos demais fragmentos, a densidade de cepos não variou entre sítios (Quadro 1).

O fragmento Pinheiros Ralos vem sendo utilizado para o manejo do gado há 70 anos. A densidade de fezes de gado e a abertura do dossel diferiram significativamente entre sítios (Quadro 1).

Entre os fragmentos submetidos ao pastoreio, São Cristóvão está em melhor estado de conservação, pois tem histórico de pastoreio recente (cerca de 40 anos), menor densidade de fezes de gado, menor densidade de cepos e menor abertura do dossel que aos demais fragmentos (Quadro 1). Apesar do histórico de pastoreio recente, a compactação do solo diferiu entre sítios, e a cobertura de pteridófitas foi maior nesse fragmento do que nos demais (Figura 2). Pteridium aquilinum (L.) Kuhn é uma pteridófita invasora bem-sucedida (revisão em MARRS e WATT, 2006) e é frequiente nesse fragmento, principalmente no sítio com baixa IP. Essa espécie surge após a abertura do dossel da floresta causada por perturbações antrópicas, é capaz de influenciar tanto a composição do banco de sementes (GHORBANI et al., 2006; SILVAe MATOS, 2006) quanto o estabelecimento de plântulas (DOLLING, 1996; TABARELLI e MANTOVANI, 1999; MEIRANETO et al., 2005).

O fragmento Gateados é o único em que o gado foi excluído, por isso não foram encontradas fezes e houve baixa compactação do solo e abertura do dossel. Além disso, ocorreu baixa densidade de cepos.

A porcentagem de cobertura do solo por gramíneas não variou significativamente entre os quatro fragmentos submetidos ao pastoreio. Não houve interação entre fragmento e IP, mas sim diferença significativa entre sítios (Quadro 2), ou seja, a porcentagem de cobertura por gramíneas foi maior no sítio com alta IP do que baixa IP, nos quatro fragmentos (Figura 2). Nos sítios mais utilizados para o manejo do gado há a formação de manchas de gramíneas, compostas principalmente por Paspalum spp., que, apesar de serem espécies nativas da região de estudo, são invasoras nos fragmentos perturbados. O fragmento Gateados, cujo gado foi excluído há 13 anos, teve baixa cobertura de gramíneas (Figura 2).
O aumento da cobertura de gramíneas devido à presença do gado ocorre, pois essas plantas possuem resistência ao pastoreio, como resultado de um processo coevolutivo, que originou em adaptações, como posição basal dos meristemas, a reprodução vegetativa, a alta taxa de reposição de folhas, a presença de órgãos de reservas subterrâneos e a alta taxa de crescimento dos indivíduos (COUGHENOUR, 1985).

As plântulas de espécies arbóreas geralmente não possuem essas adaptações e são mais suscetíveis ao pastoreio do que as gramíneas. Assim, a cobertura do solo por plântulas de espécies arbóreas foi significativamente menor nos sítios de alta IP (Quadro 2 e Figura 2) do que de baixa IP. Entretanto, houve interação entre fragmento e IP, pois no fragmento Pinheiros Ralos a cobertura do solo por plântulas arbóreas foi maior no sítio com alta IP (Figura 2). Isso, provavelmente, ocorreu, pois Pinheiros Ralos é o fragmento que tem menos diferenças nas condições ambientais entre sítios (Quadro 1).

Quadro 2 - Resultado da MANOVA (utilizando a estatística de Wilk's Lâmbda) para a comparação da porcentagem média de cobertura até $50 \mathrm{~cm}$ acima do solo de gramíneas, herbáceas e plântulas de espécies lenhosas, em função de duas variáveis dependentes, fragmento (quatro níveis) e intensidades de pastoreio (IP) (dois níveis), em Floresta Ombrófila Mista no médio rio Pelotas. O fragmento Gateados foi excluído desta análise, pois não teve sítio de alta e baixa intensidades de pastoreio

Table 2-MANOVA result (using Wilk's Lambda statistics) to test the association between ground cover percentages (grass, herbaceous seedlings, woody seedlings) up to $50 \mathrm{~cm}$ above the soil level, in function of two dependent variables, fragment (four levels) and grazing intensity (two levels), in Araucaria Forest of the Pelotas river basin. The fragment Gateados was excluded from this analysis since it does not have low and high grazing intensity sites

\begin{tabular}{lcccccr}
\hline & \multicolumn{2}{c}{ Fragmento } & \multicolumn{2}{c}{ IP } & \multicolumn{3}{c}{ Interação } \\
& $\mathrm{F}$ & $\mathrm{p}$ & $\mathrm{F}$ & $\mathrm{p}$ & $\mathrm{F}$ & $\mathrm{p}$ \\
\hline Modelo & 4,49 & $<0,001$ & 8,75 & $<0,001$ & 3,83 & $<0,001$ \\
Variáveis & & & & & & \\
dependentes & & & & & & \\
\hline Gramíneas & 0,30 & 0,83 & 12,34 & $<0,001$ & 1,33 & 0,27 \\
Herbáceas & 8,18 & $<0,001$ & 0,96 & 0,33 & 3,69 & 0,02 \\
Plântulas & 1,85 & 0,15 & 17,51 & $<0,001$ & 6,92 & $<0,001$ \\
lenhosas & & & & & & \\
\hline
\end{tabular}

R. Árvore, Viçosa-MG, v.31, n.6, p.1035-1046, 2007 


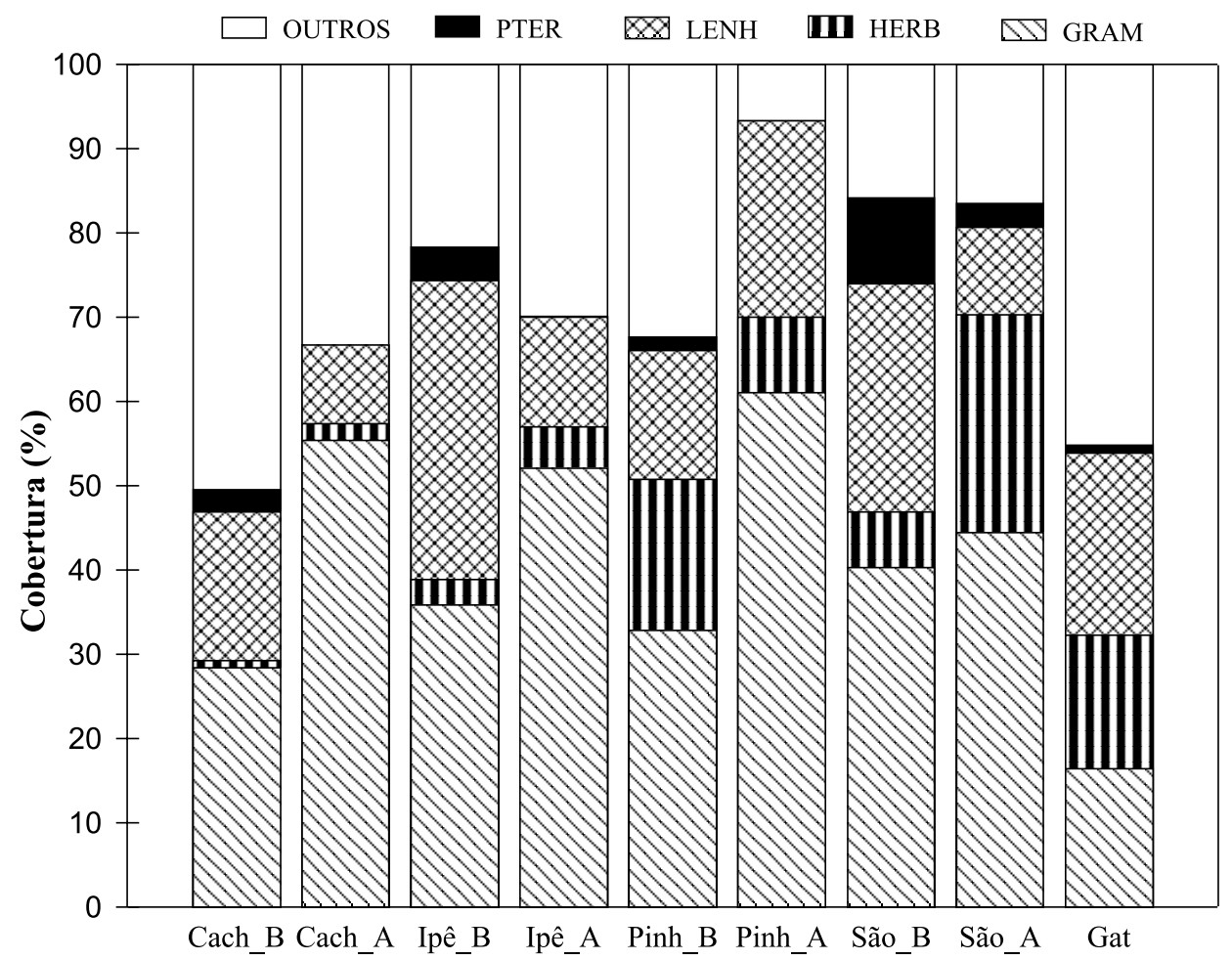

Figura 2 - Porcentagem média de cobertura até $50 \mathrm{~cm}$ acima do solo de gramíneas, herbáceas, plântulas de espécies lenhosas, pteridófitas e outros (rocha, serrapilheira, solo exposto, raízes, cipós etc.) em sítios onde o pastoreio ocorre em baixa intensidade (B) e a alta intensidade de pastoreio (A) se dá em quatro fragmentos de Floresta Ombrófila Mista no médio rio Pelotas: Cachoeirinha (Cach), Ipê, Pinheiros Ralos (Pinh), São Cristóvão (São) e Gateados (Gat).

Figure 2-Ground cover of grass, herbaceous seedlings, woody seedlings, fern and others (rock, litter, exposed soil, roots, liana, etc.) in sites with low (A) and high (B) intensity of cattle grazing in five Araucaria Forest fragments of the Pelotas river basin: Cachoeirinha (Cach), Ipê, Pinheiros Ralos (Pinh), São Cristóvão (São) and Gateados (Gat).

As pteridófitas foram abundantes nos sítios de baixa IP e ausente nos sítios submetidos a intenso pastoreio, na maioria dos fragmentos (Figura 2), à exceção do fragmento São Cristóvão, cuja cobertura por pteridófitas não variou significativamente entre sítios de diferentes intensidades de pastoreio (Mann Whitney; $\mathrm{U}=39 ; \mathrm{p}=0,41$ ). Algumas pteridófitas, apesar de serem invasoras agressivas, podem ser suscetíveis ao intenso pisoteio pelo gado.

\subsection{Estrutura populacional}

Apesar do pequeno tamanho dos fragmentos (13 a 19 ha), da sua utilização para o pastoreio e da extração seletiva de madeira, Araucaria angustifolia, Maytenus ilicifolia e Clethra scabra ocorreram em alta densidade (mais de 50 ind.ha $^{-1}$ ) pelo menos em um fragmento (Quadro 1), e as populações tenderam a possuir estrutura em "J-reverso" (Figuras 3 e 4), com maior densidade de plântulas e infantis do que de árvores, favorecendo a regeneração das populações e a sua persistência em longo prazo. A. angustifolia é uma espécie dominante na Floresta Ombrófila Mista e ocorre em alta densidade, mas nem sempre a população apresenta estrutura em "J-reverso" (SCHAAF et al., 2006).

As populações de A. angustifolia em todos os fragmentos tiveram mais infantis do que plântulas (Figura 3), pois muitas das plântulas originadas na estação de dispersão de sementes [maio a julho (SOUZA e HATTEMER, 2003)] teve tempo suficiente para alcançar a classe infantil (30 a $100 \mathrm{~cm}$ de altura) antes do período de amostragem (setembro a janeiro). Isso ocorreu, pois as sementes são recalcitrantes e começam a germinar após 13 dias da embebição (MOREIRA-SOUZA e CARDOSO, 2003), e as plântulas crescem rapidamente, podendo alcançar $23 \mathrm{~cm}$ de altura após 100 dias da germinação (EINIG et al., 1999). 


\section{Cachoeirinha}

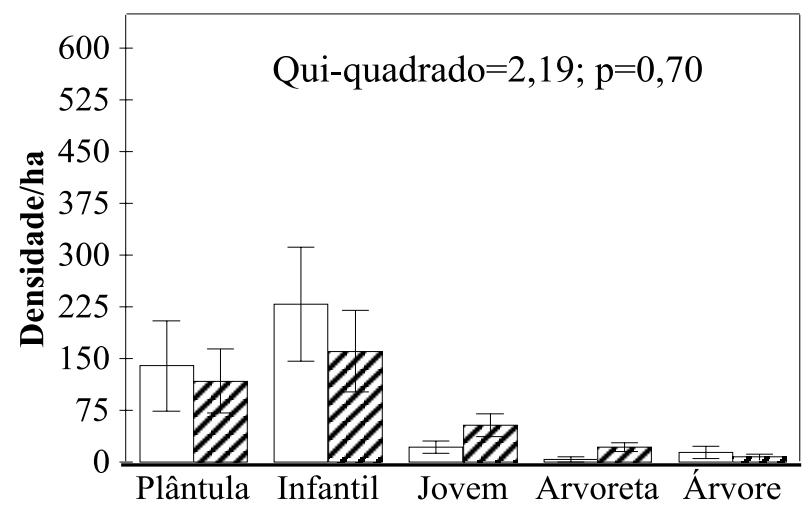

Pinheiros ralos

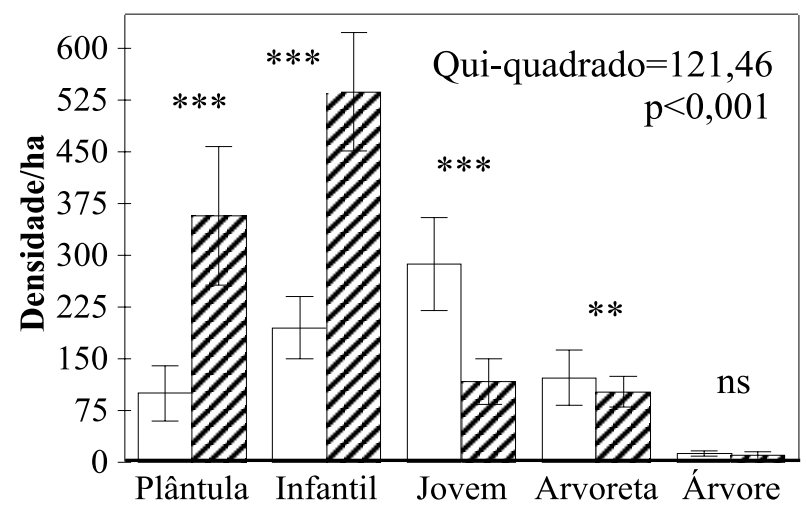

Ipê

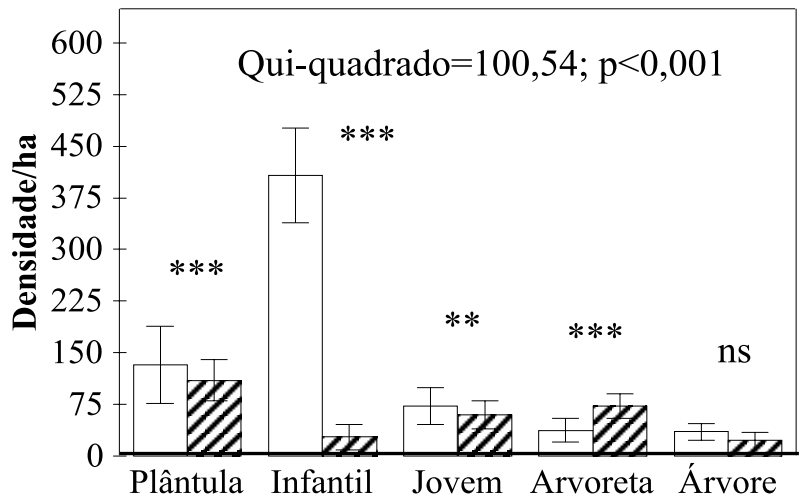

São Cristóvão

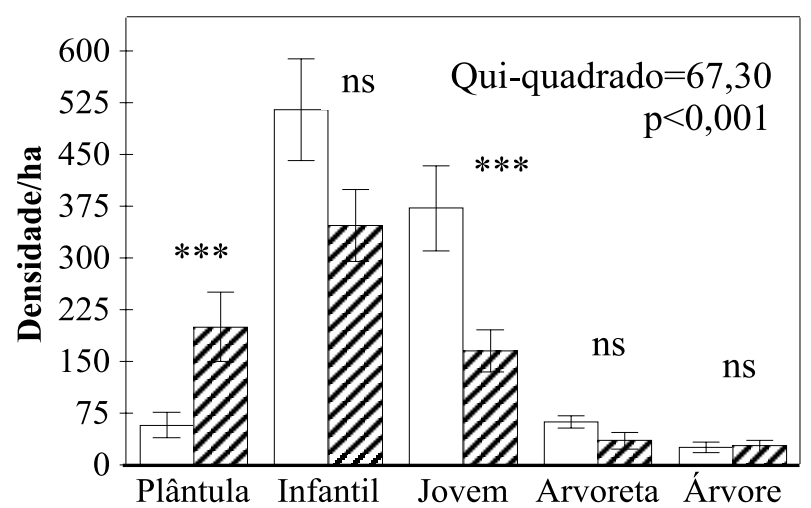

\section{Gateados}

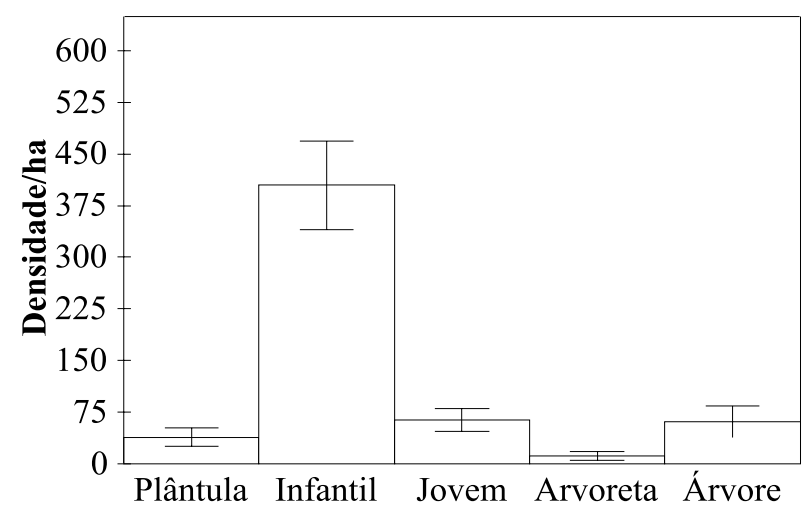

Figura 3 - Estrutura da população de Araucaria angustifolia em cinco fragmentos de Floresta Ombrófila Mista no médio rio Pelotas. As barras em branco representam sítios de baixa intensidade de pastoreio (IP) e as hachuradas, sítios de alta IP. A proporção de indivíduos foi comparada entre sítios em cada fragmento e cada estágio de vida. (**) $0,01>\mathrm{p}>0,001 ;(* * *) \mathrm{p}<0,001 ;$ e (ns) $\mathrm{p}>0,05$.

Figure 3 - Araucaria angustifolia population structure in five Araucarian Forest fragments of the Pelotas river basin. The white bars represent low intensity of cattle grazing (ICG) site and the shaded bars represent high ICG site. The proportion of individuals was compared among sites in each fragment and life stage. $(* *) 0.01>p>0.00 ;(* * *)$ $p<0.001 ;(n s) p>0.05$. 

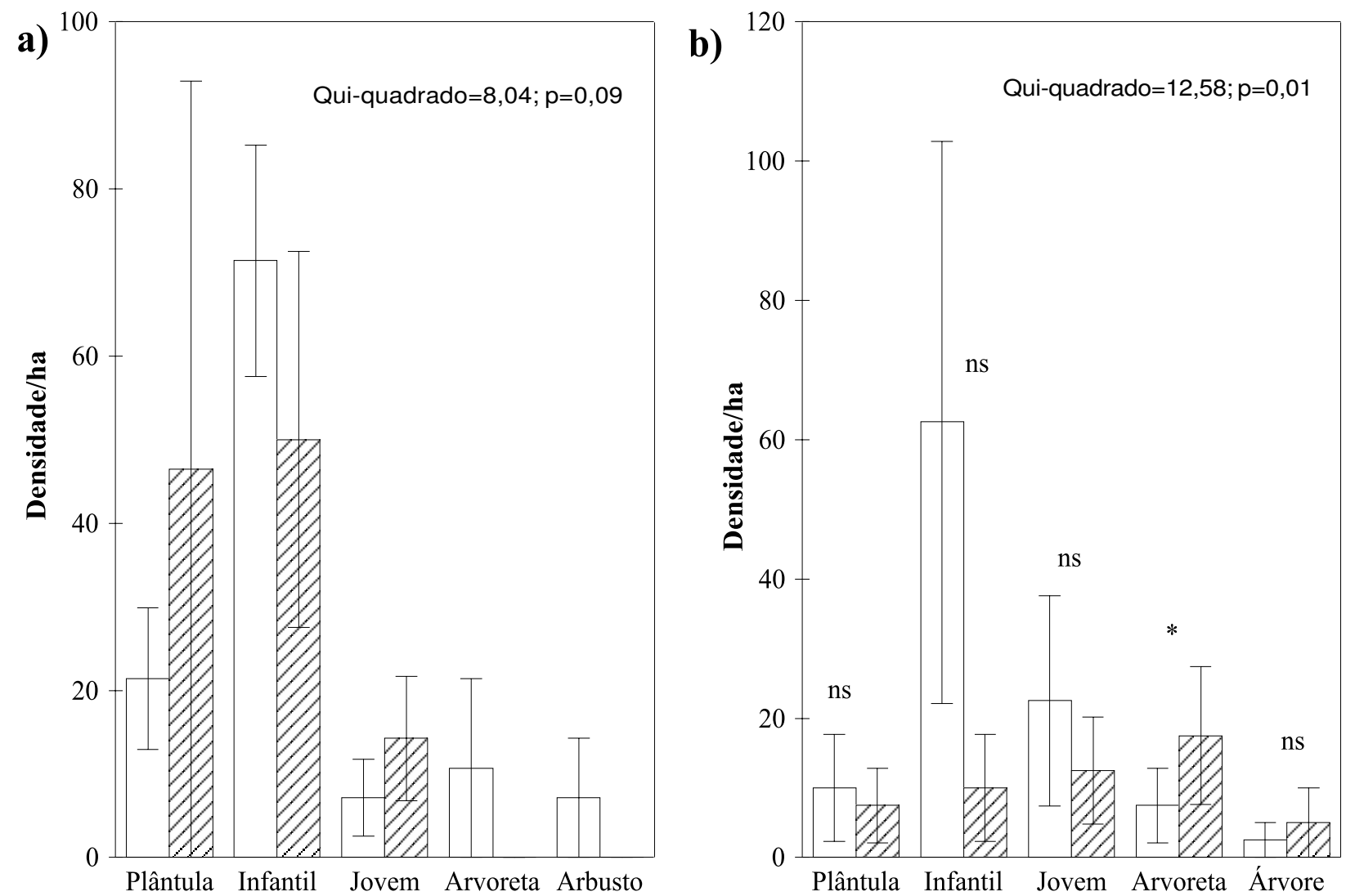

Figura 4 - Estrutura populacional de Maytenus ilicifolia (Schrad.) Planch. no fragmento Cachoeirinha (a) e Clethra scabra Pers. no fragmento Pinheiros Ralos (b), em Floresta Ombrófila Mista no médio rio Pelotas. As barras em branco representam o sítio de baixa intensidade de pastoreio e as hachuradas, o sítio de alta intensidade de pastoreio. Resultado do $\chi^{2}$ para verificar a associação entre a estrutura da população e a intensidade de pastoreio. (*) $\mathrm{p}<0,05$ $\mathrm{e}(\mathrm{ns}) \mathrm{p}>0,05$.

Figure 4-Population structure of Maytenus ilicifolia (Schrad.) Planch. in the Cachoeirinha fragment (a), and of Clethra scabra Pers. in the Pinheiros Ralos fragment (b), at Araucaria Forest in the Pelotas river basin. The white bars represent low intensity cattle grazing and the shaded bars represent high intensity cattle grazing. We used $\chi^{2}$ to verify the association between population structure and cattle grazing intensity. The proportion of individuals in each life class was tested between sites of each fragment. $(*) p<0.05 ;(n s) p>0.05$.

Entre as quatro espécies, duas são adaptadas a fragmentos sujeitos às perturbações antrópicas. As plântulas de A. angustifolia crescem em áreas de média a alta iluminação (DUARTE e DILLENBURG, 2000), sobrevivem em locais perturbados (SOARES, 1979) e são freqüentemente encontradas em pastagens (obs. pess). Clethra scabra é heliófita (ICHASO e GUIMARÃES, 1975), freqüentemente ruderal, encontrada em ambientes de alta luminosidade, como na borda e clareiras dos fragmentos (observação pessoal).

A estrutura populacional de A. angustifolia no fragmento Cachoeirinha, não diferiu significativamente entre sítios com diferentes IPs (Figura 3), mesmo sendo o fragmento submetido por mais tempo ao pastoreio (cerca de 200 anos) e suportando a maior densidade de gado (Quadro 1). Já nos demais fragmentos a estrutura populacional variou significativamente entre áreas.

No fragmento Ipê, a população do sítio de baixa IP teve maior proporção de indivíduos nos três primeiros estágios do ciclo de vida (plântulas, infantis e jovens) do que no sítio de alta IP(Figura 3). Essa diferença contribuiu para que a população no sítio com baixa IP tivesse mais do que o dobro da densidade de indivíduos do que no sítio com alta IP (Quadro 1). Isso pode ter ocorrido devido à alta variação na compactação do solo e abertura do dossel entre sítios. Apesar de a extração de madeira ter 
ocorrido com maior intensidade no sítio sujeito a alta IP do fragmento ipê (Quadro 1), não houve variação significativa na proporção de árvores (DAS $>30 \mathrm{~cm}$ ) de A. angustifolia entre sítios (Figura 3).

No fragmento Pinheiros Ralos, as duas classes iniciais (plântula e infantil) tiveram menor proporção de indivíduos no sítio com baixa IP do que com alta IP, resultado contrário ao encontrado no fragmento ipê (Figura 3).

Em São Cristóvão, os resultados foram similares aos de Pinheiros Ralos, sendo encontrada maior proporção de plântulas no sítio de alta IP, porém a proporção de indivíduos infantis não diferiu significativamente entre sítios (Figura 3). Em São Cristóvão houve menor variação nas características ambientais em função da IP.

A estrutura populacional no fragmento Gateados foi similar aos demais fragmentos (Figura 3), entretanto houve maior densidade de árvores (DAS $>30 \mathrm{~cm}$ ) de A. angustifolia no Gateados $(61,4 \pm 22,4$ ind./ha) do que nos demais fragmentos $(10,7 \pm 5,1-28,8 \pm 8,2$ ind./ha). Além de ter mais árvores, as árvores tiveram maior DAS, portanto a área basal de A. angustifolia no Gateados $\left(23,83 \pm 0,31 \mathrm{~m}^{2}\right)$ foi pelo menos três vezes maior que nos demais $\left(2,74 \pm 0,06-6,75 \pm 0,05 \mathrm{~m}^{2}\right)$.

De forma geral, os efeitos do pastoreio na estrutura de populações de $A$. angustifolia variaram entre fragmentos em função das características ambientais e do manejo do gado. A influência da heterogeneidade ambiental nos efeitos do pastoreio sobre populações de plantas também foi encontrada por Miller e Wells (2003) em Podocarpus totara G. Benn. ex D. Don na Nova Zelândia e por Relva e Veblen (1998) estudando Austrocedrus chilensis (D. Don) Pic. Serm. \& Bizzarri em florestas da Patagônia, Argentina. Alternativamente, outras variáveis não avaliadas neste estudo podem explicar a variação nas populações entre fragmentos, a exemplo da intensidade de coleta de sementes de A. angustifolia, uma atividade econômica importante, freqüente na área de estudo e que pode influenciar a densidade de plântulas recrutadas anualmente. Além disso, pode haver variações entre os fragmentos na profundidade e nas características químicas e físicas do solo, que influenciam a estrutura populacional de A. angustifolia (PUCHALSKI et al., 2006).

Dicksonia sellowiana ocorreu nos quatro fragmentos em baixa densidade (Quadro 1), mas não se pode afirmar que as populações sejam influenciadas pelo pastoreio, pois, apesar dos indivíduos não terem sido encontrados nas áreas de alta IP e terem sido encontrados nas áreas de baixa IP de dois fragmentos, nos outros dois fragmentos o resultado foi inverso (Quadro 1). Na Floresta Ombrófila Mista da região de estudo, a abundância desta espécie é maior próximo a canais de drenagem (E. S. Guarino; dados não publicados). Assim, a baixa densidade de D. sellowiana encontrada pode ser mais influenciada pela umidade do solo do que pelo pastoreio.

Maytenus ilicifolia ocorreu em alta densidade (mais de 50 ind./ha) somente em um dos fragmentos avaliados (Quadro 1), portanto os resultados não são conclusivos. Apesar disso, a estrutura da população não foi significativamente influenciada pelo pastoreio nesse fragmento (Figura 4a).

A estrutura populacional de Clethra scabra diferiu significativamente entre sítios de diferentes IPs no fragmento Pinheiros Ralos. Houve maior proporção de indivíduos infantis no sítio de baixa IP e maior proporção de arvoretas no sítio de alta IP. A proporção de indivíduos nas demais classes não diferiu entre sítios (Figura 4b). Entretanto, como a espécie ocorreu somente no fragmento com menos indícios de influência do gado (Quadro 1), os resultados também não são conclusivos.

\section{CONCLUSÕES}

Fragmentos pequenos de Floresta Ombrófila Mista no médio rio Pelotas, com longo histórico de perturbações antrópicas por extração seletiva de madeira e pastoreio de gado, possuem populações abundantes e com estrutura em "J-reverso" de Araucaria angustifolia, Maytenus ilicifolia e Clethra scabra. Os efeitos do pastoreio nas populações de A. angustifolia nesses fragmentos variam em função das características ambientais e da intensidade e freqüência de pastoreio, mas não há um padrão em resposta ao manejo do gado. Os resultados com relação aos efeitos do pastoreio nas populações das demais espécies estudadas não são conclusivos, pois ocorreram em alta densidade apenas em um fragmento.

O manejo do gado pode influenciar o tipo de cobertura do solo, o que implica variações na composição florística do subbosque. Nos sítios cujo pastoreio é intenso, há um favorecimento de gramíneas, em detrimento das

R. Árvore, Viçosa-MG, v.31, n.6, p.1035-1046, 2007 
espécies suscetíveis à herbivoria, como pteridófitas e plântulas de espécies arbóreas. Além disso, o gado aumenta a abertura do dossel e a compactação e modifica a cobertura do solo nos fragmentos, o que pode influenciar a germinação de sementes e o estabelecimento de plântulas, mas esses efeitos precisam ser mais bem avaliados.

\section{AGRADECIMENTOS}

Ao Dr. Marcelo Brilhante de Medeiros, pelas contribuições ao trabalho; a Aécio Amaral Santos, Juarez Pereira do Amaral e Sérgio Eustáquio de Noronha, pelas sugestões e auxílio nas atividades de campo; ao Luciano Coelho Milhomens Fonseca e Ísis Meri Medri, pela revisão do manuscrito; aos proprietários das Fazendas Cachoeirinha, Ipê, Pinheiros Ralos, São Cristóvão e Florestal Gateados Ltda., por autorizarem a coleta de dados; à Embrapa Recursos Genéticos e Biotecnologia, pelos recursos financeiros; e à Fundação Arthur Bernardes, pelas bolsas de estudo concedidas aos autores.

\section{REFERÊNCIAS}

BRASIL. Ministério da Agricultura. Avaliação e ações prioritárias para a conservação da biodiversidade da Mata Atlântica e Campos Sulinos. Brasília: 2000. 40p.

BROWER, J. E.; ZAR, J. H.; von ENDE, C. N. Field and laboratory methods for general ecology. Dubuque: WCB Publishers, 1989. 237p.

BURNS, B. R. Fire induced dynamics of Araucaria araucana in Nothofagus antarctica forest in the Southern Andes. Journal of Biogeography, v.20, n.6, p.669-685, 1993.

CIPRIANI, T. R. et al. A polysaccharide from a tea (infusion) of Maytenus ilicifolia leaves with antiulcer protective effects. Journal of Natural Products, v.69, n.7, p.1018-1021, 2006.

COUGHENOUR, M. B. Graminoid responses to grazing by large herbivores: Adaptations, exadaptations and interacting processes. Annals of the Missouri Botanical Garden, v.72, n.4, p.852-863, 1985.

R. Árvore, Viçosa-MG, v.31, n.6, p.1035-1046, 2007
DOLLING, A. H. U. Interference of bracken (Pteridium aquilinum L. Kuhn) with Scots pine (Pinus sylvestris L.) and Norway spruce (Picea abies L. Karst.) seedling establishment. Forest Ecology and Management, v.88, n.3, p.227-235, 1996.

DUARTE, L. D.; DILLENBURG, L. R.

Ecophysiological responses of Araucaria angustifolia (Araucariaceae) seedlings to different irradiance levels. Australian Journal of Botany, v.48, n.4, p.531-537, 2000.

EINIG, W.; MERTZ, A.; HAMPP, R. Growth rate, photosynthetic activity, and leaf development of Brazil pine seedlings (Araucaria angustifolia Bert. O. Ktze.). Plant Ecology, v.143, n.1, p.23-28, 1999.

ENRIGHT, N. J.; MILLER, B. P.; PERRY, G. L. W. Demography of the long-lived conifer Agathis ovata in maquis and rainforest, New Caledonia. Journal of Vegetation Science, v.14, n.5, p.625-636, 2003.

EVANS, D. M. et al. To graze or not to graze? Sheep, voles, forestry and nature conservation in the British uplands. Journal of Applied Ecology, v.43, n.3, p.499-505, 2006.

GATSUK, L. E. et al. Age states of plants of various growth forms - a review. Journal of Ecology, v.68, n.2, p.675-696, 1980.

GHORBANI, J. et al. Effects of the litter layer of Pteridium aquilinum on seed banks under experimental restoration. Applied Vegetation Science, v.9, n.1, p.127-136, 2006.

HEGLAND, S. J.; van LEEUWEN, M.; OOSTERMEIJER, J. G. B. Population structure of Salvia pratensis in relation to vegetation and management of Dutch dry floodplain grasslands. Journal of Applied Ecology, v.38, n.6, p.1277-1289, 2001.

IBAMA. Lista oficial de flora ameaçada de extinção. Disponível em: (www.ibama.gov.br). Acessado em: 12 de fevereiro de 2007.

ICHASO, C. L. F.; GUIMARÃES, E. F. Cletráceas. In: REITZ, P. R. (Ed.). Flora ilustrada catarinense. Itajaí: Herbário Barbosa Rodrigues, 1975. 19p. 
IUCN 2006. IUCN Red List of Threatened Species. Disponível em :(www.iucnredlist.org). Acessado em: 12 de fevereiro de 2007.

KLEIJN, D.; STEINGER, T. Contrasting effects of grazing and hay cutting on the spatial and genetic population structure of Veratrum album, an unpalatable, long-lived, clonal plant species. Journal of Ecology, v.90, n.2, p.360-370, 2002.

KLEIN, R. M. Mapa fitogeográfico do estado de Santa Catarina. Itajaí: SUDESUL/FATMA/HBR, 1978. 24p.

LEITE, J. P. V. et al. Isolation and HPLC Quantitative analysis of flavonoid glycosides from brazilian beverages (Maytenus ilicifolia and M. aquifolium). Journal of Agricultural and Food Chemistry, v.49, n.8, p.3796-3801, 2001.

LEMMON, P. E. A new instrument for measuring forest overstory density. Journal of Forestry, v.55, n.9, p.667-668, 1957.

LIEBSCH, D.; ACRA, L. A. Riqueza de espécies de sub-bosque de um fragmento de Floresta Ombrófila Mista em Tijucas do Sul, PR. Ciência Florestal, v.14, n.1, p.67-76, 2004.

MACHADO, R. E. Padrões vegetacionais em capões de Floresta com Araucária no planalto nordeste do Rio Grande do Sul, Brasil. 2004. 164 f. Dissertação (Mestrado em Ecologia).Universidade Federal do Rio Grande do Sul, Porto Alegre, 2004.

MALUF, J. R. T. Nova classificação climática do Estado do Rio Grande do Sul. Revista Brasileira de Agrometeorologia, v.8, n.1, p.141-150, 2000.

MARRS, R. H.; WATT, A. S. Biological flora of the British Isles: Pteridium aquilinum (L.) Kuhn. Journal of Ecology, v.94, n.6, p.1272-1321, 2006.

MAUHS, J. Fitossociologia e regeneração natural de um fragmento de Floresta Ombrófila Mista exposto a perturbações antrópicas. 2002. $66 \mathrm{f}$. Dissertação (Mestrado em Diversidade e Manejo de Vida Silvestre). UNISINUS, São Leopoldo, 2002.
MEIRA NETO, J. A. A. et al. Floristic composition, biological spectrum and phytophysiognomy of muçununga vegetation at Caravelas and Mucuri municipalities, Bahia state, Brazil. Revista Árvore, v.29, n.1, p.139-150, 2005.

MILLER, C.; WELLS, A. Cattle grazing and the regeneration of totara (Podocarpus totara var. waihoensis) on river terraces, south Westland, New Zealand. New Zealand Journal of Ecology, v.27, n.1, p.37-44, 2003.

MOREIRA-SOUZA, M.; CARDOSO, E. J. B. N. Método prático para germinação de sementes de Araucaria angustifolia (Bert.) O. Ktze. Scientia Agricola, v.60, n.2, p.389-391, 2003.

POTTER, R. O. et al. Solos do Estado de Santa Catarina. Rio de Janeiro: Embrapa Solos, 2004. 726p. (Boletim de Desenvolvimento, 46)

PUCHALSKI, Â.; MANTOVANI, M.; REIS, M. S. D. Variação em populações naturais de Araucaria angustifolia (Bert.) O.Kuntze associada a condições edafo-climáticas. Scientia Forestalis, v.70, p.137-148, 2006.

RELVA, M. A.; VEBLEN, T. T. Impacts of introduced large herbivores on Austrocedrus chilensis forests in northern Patagonia, Argentina. Forest Ecology and Management, v.108, n.1-2, p.27-40, 1998.

SCHAAF, L. B. et al. Diametric structure changes in a ombrophyllous mixed forest between 1979 and 2000. Revista Árvore, v.30, n.2, p.283-295, 2006.

SEMA. Lista das espécies da flora ameaçadas de extinção no Rio Grande do Sul. Disponível em: (www.sema.rs.gov.br). Acessado em: 12 de fevereiro de 2007.

SILVA, U. D. S. R.; MATOS, D. M. S. The invasion of Pteridium aquilinum and the impoverishment of the seed bank in fire prone areas of Brazilian Atlantic Forest.

Biodiversity and Conservation, v.15, n.9, p.3035-3043, 2006.

SOARES, R. V. Considerações sobre a regeneração natural da Araucaria angustifolia. Revista Floresta, v.10, n.2, p.12-18, 1979.

R. Árvore, Viçosa-MG, v.31, n.6, p.1035-1046, 2007 
SOUZA, V. A.; HATTEMER, H. H. Fenologia reprodutiva de Araucaria angustifolia no Brasil. Boletim de Pesquisa Florestal, v.47, p.19-32, 2003.

SUN, D.; DICKINSON, G. R.; BRAGG, A. L. Effect of cattle grazing and seedling size on the establishment of Araucaria cunninghamii in a silvo-pastoral system in northeast Australia. Journal of Environmental

Management, v.49, n.4, p.435-444, 1997.

TABARELLI, M.; MANTOVANI, W. A regeneração de uma floreata tropical montana após corte e queima (São Paulo-Brasil). Revista Brasileira de Biologia, v.59, n.2, p.239-250, 1999.

VARGAS, O.; PREMAUER, J.; CÁRDENAS, C. A. Efecto del pastoreo sobre la estructura de la vegetación en un paramo húmedo de Colombia. Ecotrópicos, v.15, n.1, p.35-50, 2002.
VELLOSA, J. C. R. et al. Antioxidant activity of Maytenus ilicifolia root bark. Fitoterapia, v.77, n.3, p.243-244, 2006.

VELOSO, H. P.; RANGEL FILHO, A. L. R.; LIMA, J. C. A. Classificação da vegetação brasileira adaptada a um sistema universal. São Paulo: Fundação Instituto Brasileiro de Geografia e Estatística, 1991. 123p.

WATKINSON, A. R. Plant population dynamics. In: CRAWLEY, M. J. (Ed.). Plant population dynamics. Oxford: Blackwell Science, 1997. p 400-559.

WILSON, H. D. Regeneration of native forest on Hinewai reserve, Banks peninsula. New Zealand Journal of Botany, v.32, n.3, p.373-383, 1994. 